\title{
Comparative analysis and design of tower using diagrid, conventional moment frame and braced frame system of steel structures
}

\author{
Made Sukrawa ${ }^{1 *}$, Gede Pringgana ${ }^{1}$, and Putu Diva Tryatra Sanjaya ${ }^{1}$ \\ ${ }^{1}$ Department of Civil Engineering, Universitas Udayana, Denpasar, Indonesia
}

\begin{abstract}
The diagrid structure system has become an encouraging alternative for the construction of tall buildings partly because of the aesthetic reason. Structurally, the system also interesting because its diagonal intersecting members are capable of resisting vertical and lateral forces efficiently. This research compared the design of steel tower building using diagrid (DIA) system and the more commonly used systems, moment frame (MF) and braced frame (BF). Numerical modelling using finite element software ETABS were conducted to design a 10-story building of $15 \times 15 \mathrm{~m}$ with total height of 50 meters. The seismic behaviors of all models were compared under the same loading conditions. From the analysis results the DIA model showed superior seismic behavior followed by BF and MF. The DIA model was not only stiffer than the others, but also required smaller volume of steel.
\end{abstract}

\section{Introduction}

Construction of tall towers has become trends everywhere to attract attention and become the landmark of the place where it is built. Diagrid is one of the structural systems that become an encouraging alternative for the construction of a steel tower along with another structural system such as truss, conventional moment frame, and braced frame. Eifel Tower in Paris, France is one of the most popular tourist attractions built using vertical truss system and similarly, John Hancock Tower in Chicago was built using braced frame [1]. Many other attractive towers were built using conventional moment frame (MF), braced frame (BF) and diagonal grid or diagrid (DIA) structural systems. Between the three systems, MF is most widely used due to the simplicity and convenience provided by the rectangular shape [2]. BF, however, is always more efficient and economical than MF [3]. Both MF and BF have been listed as seismic load resisting system in both ASCE/SEI 7-10 and AISC 341-10 [4,5] with values of seismic response modification factors such as seismic response modification coefficient, $\mathrm{R}$, overstrength factor, $\Omega_{0}$, and deflection amplification factors, $\mathrm{C}_{\mathrm{d}}[6]$. DIA as a new alternative structural system is not yet listed in the above-mentioned table. DIA, however, is believed to be a better choice concerning aesthetic, efficiency and lateral stiffness for the case of special shaped and very tall tower of 20 stories and higher. A study suggested that DIA is more efficient and laterally stiffer

${ }^{*}$ Corresponding author: msukrawa@yahoo.com 
than MF because the diagonal grid is capable of resisting shear and axial forces [7-9]. Comparison between the three systems, are not yet clear and need to be investigated.

In this paper, the application of the three structural systems, DIA, MF, and BF, were compared for the design of 10 stories tower building subjected to seismic loading. The structures consist of 4 core columns and 12 exterior columns for MF and BF. For DIA, the exterior consists of a diagonal grid with 12 footings. The comparison includes the seismic properties and efficiency. The seismic properties include natural period, lateral stiffness, and internal forces due to seismic loading combination. For the efficiency, the volume of steel material required for the three structural systems was compared.

\section{Methods}
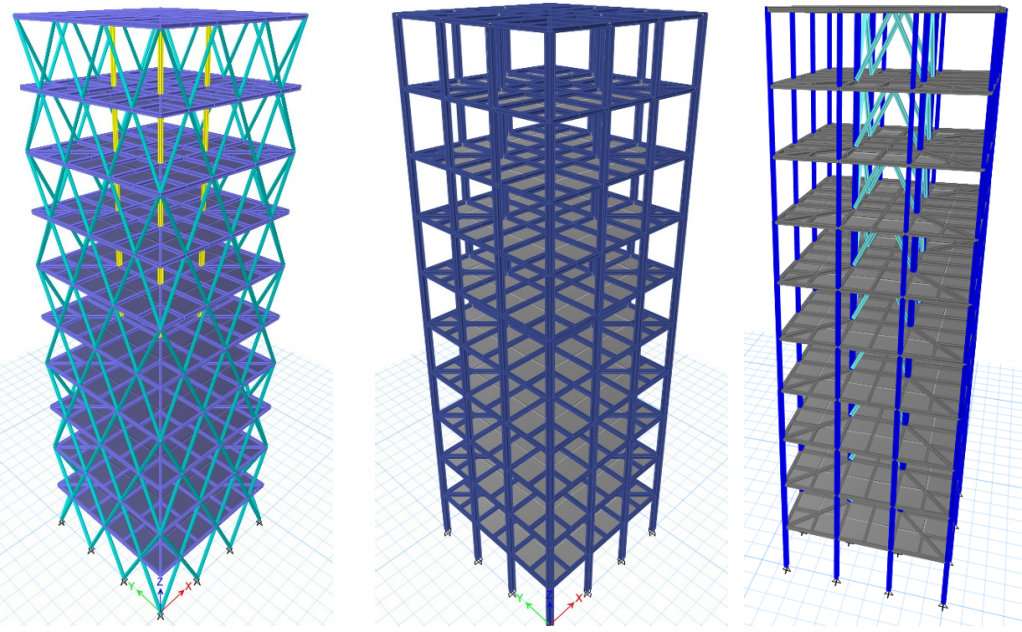

Fig. 1. The 3-D models of DIA (left), MF (center) and BF (right).

Finite element models of DIA, MF, and BF were created in ETABS software as shown in Fig. 1. The models were used for the design of 10 story tower building of 15 by 15 meters with a total height of 50 meters. The three-dimensional models were vertically loaded with a live load of $3.59 \mathrm{kN} / \mathrm{m}^{2}$ for the typical floor and $0.96 \mathrm{kN} / \mathrm{m}^{2}$ for the roof according to ASCE/SEI 7-10 provisions [4]. For the lateral load, seismic load and wind load were considered using load combination of vertical and lateral (i.e., 1.2D $+\mathrm{L}+\mathrm{E}, 1.2 \mathrm{D}+\mathrm{L}+\mathrm{W}$, etc.). The seismic load was applied using static equivalent using auto lateral load feature in the software and response spectrum analysis (RSA) with Ss and S1 of 0.663 and 0.248 , respectively. For the wind load, a maximum velocity of $23.36 \mathrm{mph}$ (20.3 knots) was used that represent the Surabaya area in East Java, Indonesia.

Table 1. Values of R, $\Omega_{0}$ and $C_{d}$ for DIA, SMF and SCBF.

\begin{tabular}{|c|c|c|c|}
\hline Coef. and factors & DIA & Special MF & Special BF \\
\hline $\mathrm{R}$ & 4 & 8 & 7 \\
\hline 0 & 1.5 & 3 & 2.5 \\
\hline $\mathrm{C}_{\mathrm{d}}$ & 2.5 & 5.5 & 5.5 \\
\hline
\end{tabular}


Design coefficients and factors for seismic-force-resisting systems of MF and BF were taken based on ASCE/SEI 7-10 for special MF and special concentric BF [4]. For the DIA system, however, values suggested in another reference [10] were shown in Table 1.

The three models were checked to satisfy strength and stiffness requirement according to AISC 360-10 [11] and ASCE/SEI 7-10 codes [4]. After the strength requirement was satisfied, then the design was continued with the stiffness requirement check. The results were considered final after both requirements were satisfied. The structural steel weight of all models was also compared for efficiency investigation.

\subsection{Stress ratio}

The stress ratios were used to determined member dimensions based on strength requirement. For the stress ratio control, the AISC equation for doubly and singly symmetric members subject to flexure and compression were used Eq. 1 and 2 [11].

$$
\begin{aligned}
\text { If } \frac{P_{r}}{P_{c}} \geq 0.2: & \frac{P_{r}}{P_{c}}+\frac{8}{9}\left(\frac{M_{r x}}{M_{c x}}+\frac{M_{r y}}{M_{c y}}\right) \leq 1 \\
\text { If } \frac{P_{r}}{P_{c}} \leq 0.2: & \frac{P_{r}}{2 P_{c}}+\left(\frac{M_{r x}}{M_{c x}}+\frac{M_{r y}}{M_{c y}}\right) \leq 1
\end{aligned}
$$

where $P_{r}=$ required axial strength using LRFD or ASD load combinations, $(\mathrm{N}), P_{c}=$ available axial strength, (N), $M_{r}$ = required flexural strength using LRFD or ASD load combinations, $(\mathrm{N}-\mathrm{mm}), M_{c}=$ available flexural strength, $(\mathrm{N}-\mathrm{mm}), x=$ subscript relating symbol to strong axis bending, $y=$ subscript relating symbol to weak axis bending.

\subsection{Drift control}

The lateral stiffness requirements were checked using maximum drift control in Eq. 3 according to the ASCE/SEI 7-10 specification [4]. The maximum inter-story drift should not exceed $0.020 \mathrm{hsx}$.

$$
\Delta_{x}=\frac{\left(\delta_{x e^{-\delta}} x-1 e^{) \times C} d\right.}{I_{E}} \leq \Delta_{a}
$$

where $\Delta_{x}=$ story drift of story $\mathrm{x}, \Delta_{a}=$ allowable story drift, $\delta_{x e}=$ elastic deflection of level $\mathrm{x}, \delta_{x-l e}=$ elastic deflection of level x-1, $C_{d}=$ deflection amplification factor, $I_{E}=$ importance factor, $h_{s x}=$ story height below level $\mathrm{x}$.

\subsection{Steel shape, dimension and join types}

The three models were designed using a trial member dimension. All members of the models use WF shape except the diagonal grid of DIA that used round HSS shape. The dimensions were adjusted to conform with strength and stiffness requirements. The beam to column connection of all models is rigid. Pin connection was used for the brace to frame join and all join of the diagrid members. 


\section{Results and discussion}

\subsection{Dimension, internal forces, and stress ratio}

The dimension of structural members was obtained from design and analysis using ETABS software. All dimensions were determined by trial to meet stress ratio less than 1.0 according to AISC $360-10$ provisions [11] and inter-story drift ratio not to exceed $0.020 \mathrm{hsx}$ according to ASCE/SEI 7-10 specifications [4]. The final dimensions of all structural members are shown in Table 2 . The dimension of bracings used in the BF model were WF 250 - 73 for story $1-4$ and WF 200 - 46 for story $5-10$.

Table 2. Dimension of structural members.

\begin{tabular}{|c|c|c|c|c|c|c|c|c|c|}
\hline \multirow{2}{*}{ Story } & \multicolumn{3}{|c|}{ DIA } & \multicolumn{3}{|c|}{ MF } & \multicolumn{3}{|c|}{ BF } \\
\hline & $\begin{array}{l}\text { Core } \\
\text { Col. }\end{array}$ & $\begin{array}{l}\text { Ext. Col. } \\
\text { (Diagrid) }\end{array}$ & Beam & $\begin{array}{l}\text { Core } \\
\text { Col. }\end{array}$ & $\begin{array}{l}\text { Ext. } \\
\text { Col. }\end{array}$ & Beam & $\begin{array}{l}\text { Core } \\
\text { Col. }\end{array}$ & Ext. Col. & Beam \\
\hline $1-2$ & $\begin{array}{c}\text { WF } 300 \\
-158\end{array}$ & $\begin{array}{c}\text { Rnd HSS } \\
180-52\end{array}$ & $\begin{array}{c}\text { WF } 250 \\
-22\end{array}$ & $\begin{array}{c}\text { WF } 400 \\
-467\end{array}$ & $\begin{array}{c}\text { WF } 400 \\
-467\end{array}$ & $\begin{array}{c}\text { WF } 400 \\
-106\end{array}$ & $\begin{array}{c}\text { WF } 350 \\
-223\end{array}$ & $\begin{array}{c}\text { WF } 250 \\
-80\end{array}$ & $\begin{array}{c}\text { WF } 250 \\
-22\end{array}$ \\
\hline $3-4$ & $\begin{array}{c}\text { WF } 300 \\
-158\end{array}$ & $\begin{array}{c}\text { Rnd HSS } \\
175-39\end{array}$ & $\begin{array}{c}\text { WF } 250 \\
-22\end{array}$ & $\begin{array}{c}\text { WF } 400 \\
-235\end{array}$ & $\begin{array}{c}\text { WF } 400 \\
-235\end{array}$ & $\begin{array}{c}\text { WF } 300 \\
-60\end{array}$ & $\begin{array}{c}\text { WF } 350 \\
-223\end{array}$ & $\begin{array}{c}\text { WF } 250 \\
-80\end{array}$ & $\begin{array}{c}\text { WF } 250 \\
-22\end{array}$ \\
\hline $5-6$ & $\begin{array}{c}\text { WF } 250 \\
-107\end{array}$ & $\begin{array}{c}\text { Rnd HSS } \\
150-34\end{array}$ & $\begin{array}{c}\text { WF } 250 \\
-22\end{array}$ & $\begin{array}{c}\text { WF } 350 \\
-189\end{array}$ & $\begin{array}{c}\text { WF } 350 \\
-189\end{array}$ & $\begin{array}{c}\text { WF } 250 \\
-55\end{array}$ & $\begin{array}{c}\text { WF } 300 \\
-266\end{array}$ & $\begin{array}{c}\text { WF } 200 \\
-60\end{array}$ & $\begin{array}{c}\text { WF } 250 \\
-22\end{array}$ \\
\hline 7 & $\begin{array}{c}\text { WF } 250 \\
-107\end{array}$ & $\begin{array}{c}\text { Rnd HSS } \\
150-23\end{array}$ & $\begin{array}{c}\text { WF } 250 \\
-22\end{array}$ & $\begin{array}{c}\text { WF } 350 \\
-189\end{array}$ & $\begin{array}{c}\text { WF } 350 \\
-189\end{array}$ & $\begin{array}{c}\text { WF } 250 \\
-55\end{array}$ & $\begin{array}{c}\text { WF } 300 \\
-266\end{array}$ & $\begin{array}{c}\text { WF } 200 \\
-60\end{array}$ & $\begin{array}{c}\text { WF } 250 \\
-22\end{array}$ \\
\hline 8 & $\begin{array}{c}\text { WF } 200 \\
-60\end{array}$ & $\begin{array}{c}\text { Rnd HSS } \\
150-23\end{array}$ & $\begin{array}{c}\text { WF } 250 \\
-22\end{array}$ & $\begin{array}{c}\text { WF } 350 \\
-177\end{array}$ & $\begin{array}{c}\text { WF } 350 \\
-177\end{array}$ & $\begin{array}{c}\text { WF } 250 \\
-55\end{array}$ & $\begin{array}{c}\text { WF } 200 \\
-60\end{array}$ & $\begin{array}{c}\text { WF } 200 \\
-52\end{array}$ & $\begin{array}{c}\text { WF } 250 \\
-22\end{array}$ \\
\hline $9-10$ & $\begin{array}{c}\text { WF } 200 \\
-60\end{array}$ & $\begin{array}{c}\text { Rnd HSS } \\
125-14\end{array}$ & $\begin{array}{c}\text { WF } 250 \\
-22\end{array}$ & $\begin{array}{c}\text { WF } 350 \\
-177\end{array}$ & $\begin{array}{c}\text { WF } 350 \\
-177\end{array}$ & $\begin{array}{c}\text { WF } 250 \\
-55\end{array}$ & $\begin{array}{c}\text { WF } 200 \\
-60\end{array}$ & $\begin{array}{c}\text { WF } 200 \\
-52\end{array}$ & $\begin{array}{c}\text { WF } 250 \\
-22\end{array}$ \\
\hline Roof & - & - & $\begin{array}{c}\text { WF } 250 \\
-22\end{array}$ & - & - & $\begin{array}{c}\text { WF } 250 \\
-55\end{array}$ & - & - & $\begin{array}{c}\text { WF } 250 \\
-22\end{array}$ \\
\hline $\begin{array}{l}\text { Stress } \\
\text { Ratio }\end{array}$ & $\begin{array}{c}0.172- \\
0.935\end{array}$ & $\begin{array}{c}0.287- \\
0.920\end{array}$ & $\begin{array}{c}0.015- \\
0.567\end{array}$ & $\begin{array}{c}0.112- \\
0.487\end{array}$ & $\begin{array}{c}0.120- \\
0.302\end{array}$ & $\begin{array}{c}0.079- \\
0.373\end{array}$ & $\begin{array}{c}0.336- \\
0.926\end{array}$ & $\begin{array}{c}0.330- \\
0.863\end{array}$ & $\begin{array}{c}0.110- \\
0.490\end{array}$ \\
\hline
\end{tabular}

Values of stress ratio shown in Table 2 were higher for DIA and BF systems because the member size in both systems was controlled by its strength instead of lateral stiffness. For the MF system, however, the design was controlled by lateral stiffness requirement. Therefore, a lower value of stress ratio was obtained.

The distribution of internal forces on the members of all models were also investigated. The ratio of internal forces for the three structural systems were shown in Table 3 . It is obvious from the table that most of the forces in MF and BF were higher than those of DIA. The beam bending moment on the lower floor of BF was smaller than those of DIA, and so was the beam shear. The core section in BF acted like a truss that makes the beam moment and shears smaller than those of DIA and MF. The axial force in the core column of MF was low because of its location away from the perimeter. In general, the force distribution increased from DIA to BF and MF. Accordingly, the strength requirement will follow the trend. 
Table 3. Internal forces ratio relative to DIA system.

\begin{tabular}{|c|c|c|c|c|c|c|c|c|}
\hline \multirow{2}{*}{ Story } & \multicolumn{4}{|c|}{ Bending Moments } & \multicolumn{2}{c|}{ Shear Forces } & \multicolumn{2}{c|}{ Axial Forces } \\
\cline { 2 - 10 } & \multicolumn{2}{|c|}{ MF } & \multicolumn{2}{c|}{ BF } & MF & BF & MF & BF \\
\cline { 2 - 10 } & beam & core col. & beam & core col. & beam & beam & core col. & core col. \\
\hline 2 & 6.93 & 17.42 & 0.58 & 3.08 & 4.05 & 0.56 & 0.86 & 1.24 \\
\hline 3 & 3.41 & 6.80 & 0.63 & 2.61 & 2.55 & 0.58 & 0.84 & 1.18 \\
\hline 4 & 3.49 & 4.93 & 0.66 & 3.08 & 2.52 & 0.57 & 0.83 & 1.14 \\
\hline 5 & 2.82 & 4.44 & 0.66 & 2.51 & 2.25 & 0.59 & 0.83 & 1.12 \\
\hline 6 & 2.74 & 6.35 & 0.66 & 3.49 & 2.19 & 0.60 & 0.82 & 1.09 \\
\hline 7 & 2.60 & 4.63 & 0.67 & 3.43 & 2.14 & 0.61 & 0.82 & 1.06 \\
\hline 8 & 2.45 & 3.73 & 0.64 & 3.25 & 2.04 & 0.61 & 0.82 & 1.02 \\
\hline 9 & 2.22 & 6.33 & 0.58 & 3.60 & 1.96 & 0.62 & 0.82 & 0.92 \\
\hline 10 & 2.01 & 4.53 & 0.59 & 3.15 & 1.83 & 0.62 & 0.83 & 0.79 \\
\hline Roof & 1.76 & 4.52 & 0.65 & 3.99 & 1.85 & 0.66 & 0.94 & 0.77 \\
\hline
\end{tabular}

\subsection{Story displacement, inter-story drift, and natural period}

All three models are loaded equally with lateral load due to earthquake and wind. For the seismic load, a total load of $411 \mathrm{kN}$ (base shear of MF) were applied to all models. For the wind load, a maximum velocity of $23.36 \mathrm{mph}$ was used. The story displacements were plotted in Fig. 2 together with the displacements due to wind load. It is apparent from the plot that the effect of wind load is not as significant as that of the seismic load. It means that for seismic design category $\mathrm{D}$, the effect of wind load on the lateral system need not be considered. The wind effect on the facade of the building should be investigated separately.

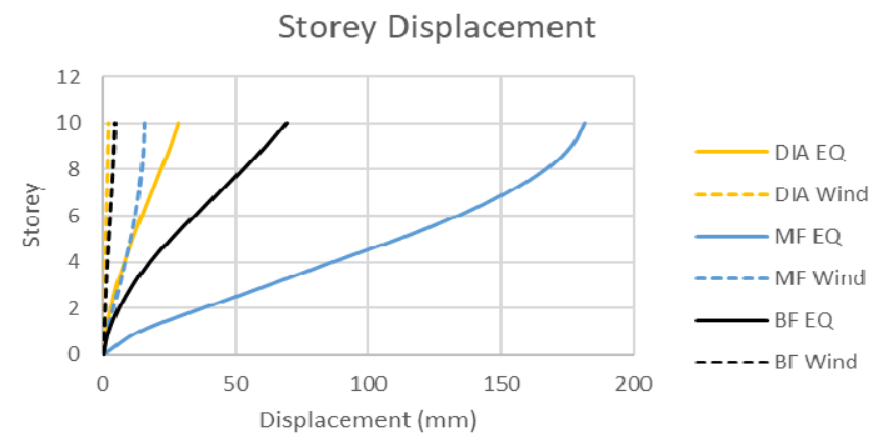

Fig. 2. Story displacement due to load combination of $1.2 \mathrm{D}+\mathrm{L}+\mathrm{E}$ and $1.2 \mathrm{D}+\mathrm{L}+\mathrm{W}$.

The inter-story drift in X-direction due to design seismic load using the corresponding $\mathrm{R}$ values was plotted in Fig. 3. The values have been factored using the corresponding value of $\mathrm{C}_{\mathrm{d}}$ for each type of structure. It is clear from the plot that the MF model shows interstory drift value closest to the limiting value of $2 \%$. The other two models show values 
much less than the limit. It means that, with the chosen size of geometry and frame members, the design of the MF model was dictated by its lateral stiffness, while the other two models were controlled by its strength. The DIA system is stiffer than the BF system, and the MF system shows the most flexible response. These results were in line with the natural period of all models; they are 1.44, 2.23, and 4.00 seconds for the DIA, BF, and MF respectively. For all models, however, there is no extreme inter-story drift detected and hence, the soft story mechanism is not an issue. It is worth mentioning that the MF model with the highest natural period will be subjected to less earthquake force compared to the other two models. At the same time, being the most flexible, the MF model is the most hazardous for non-structural damage, and therefore, it is not desirable for tower structure that containing glass façade.

\subsection{Steel weight and connections}

Total steel weight required for each model are shown in Fig. 4. The ratio of steel weight relative to DIA are 2.72 and 1.33 for MF and BF models, respectively. DIA model has the least steel weight, and hence DIA model is the most efficient among the three models. Comparison of connections was done assuming end plate type for the beam to column connection. The required end plate thickness and bolt increase from BF to DIA to MF following the magnitude of bending moment. The number of connections/ joints is 196, 176, and 216 for the DIA, MF, and BF, respectively. The MF system has the least number of connections/joints compared to the other two systems. This joint may affect the speed of construction as well as the labor cost.

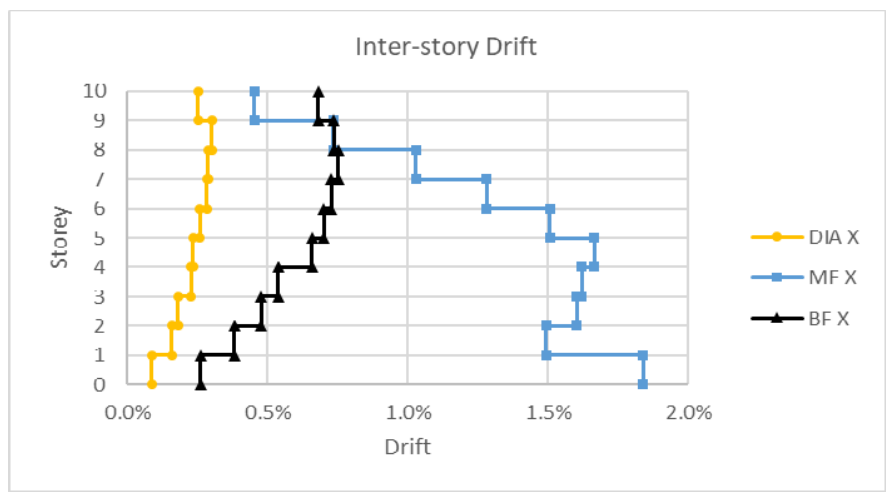

Fig. 3. Inter-story drift due to load combination of $1.2 \mathrm{D}+\mathrm{L}+\mathrm{E}$.

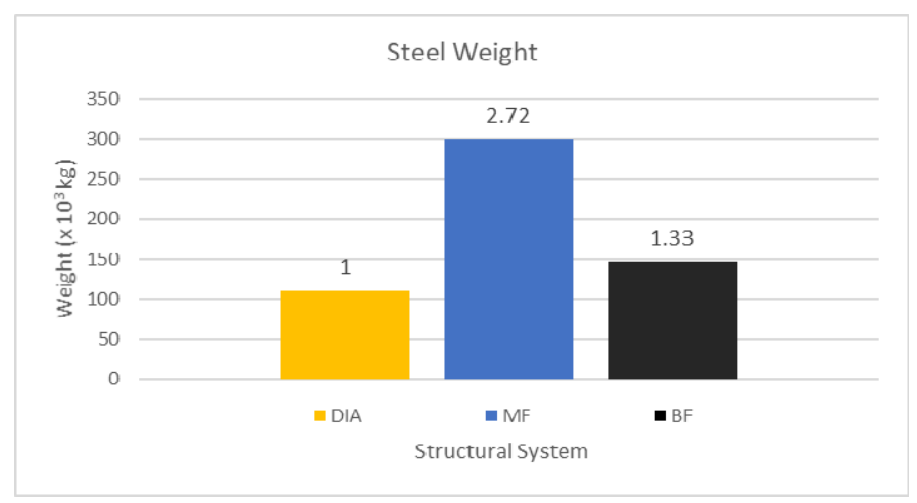

Fig. 4. Comparison of steel weight. 


\section{Conclusions}

Comparative analysis and design of diagrid (DIA), moment frame (MF), and braced frame (BF) structural systems applied for a 10-story steel tower revealed that the DIA system showed superior seismic behavior followed by BF and MF. The DIA model was not only stiffer but also required less steel than BF and MF models. The natural period of the three models were 1.44, 2.23, and 4.00 seconds for DIA, BF, and MF models, respectively. The ratio of steel weight required for the $\mathrm{BF}$ and $\mathrm{MF}$ models were 1.33 and 2.72 compared to that of DIA model. Interestingly enough, the design of the MF model was dictated by its lateral stiffness, while the other two models were controlled by its strength. It is worth noting that, with the longest natural period and hence most flexible, the MF model may be subjected to the least earthquake force among the three models.

Further study is necessary to investigate the performance of the three models loaded to failure because the seismic coefficient and factors for each model were different. Comparison of the cost of each model is also important considering differential price for different shapes, geometry, and type of joint connections.

\section{References}

1. B.S. Taranath, Structural analysis and design of tall buildings (CRC Press, Boca Raton, 2012)

2. B.S. Smith, A. Coull, Tall building structures: analysis and design (John Wiley \& Son, New Jersey, 1991)

3. D. Richard, Steel moment frames 101: What to consider when creating wide-open. Available at: https://csengineermag.com/article/steel-moment-frames-101-what-toconsider-when-creating-wide-open-spaces/ (2014)

4. ASCE, Minimum Design Loads for Buildings and others Structures ASCE/SEI 7-1 (American Society of Civil Engineering, Virginia, 2011)

5. AISC, Seismic Provisions for Structural Steel Buildings AISC 341-10 (American Institute of Steel Construction, Chicago, 2010)

6. FEMA, Quantification of Building Seismic Performance Factors FEMA P695 (Federal Emergency Management Agency, Washington DC, 2009)

7. R.D. Deshpande, S.M. Patil, S. Ratan, Int. Res. J. Eng. Tech. 2, 2295 (2015)

8. M.I. Shah, S.V. Mevada, V.B. Patel, Int. J. Eng. Res. Appl. 6, 22 (2016)

9. T.M. Boake, Diagrid structures: systems, connections, details (Birkhauser, Basel, 2014)

10. W. Baker, C. Besjak, M. Sarkisian, P. Lee, C.S. Doo, Proc. of the CTBUH $13^{\text {th }}$ US Japan Workshop (2010)

11. AISC, Specification for Structural Steel Buildings AISC 360-10 (American Institute of Steel Construction, Chicago, 2010) 